\section{New Trends and Issues Proceedings on Humanities and Social Sciences}

Issue 9 (2016) 18-26

ISSN 2421-8030

www.prosoc.eu

Selected paper of 3rd Global Conference on Linguistics and Foreign Language Teaching (LINELT 2015) 16-18 November 2015, Istanbul University, Istanbul - Turkey

\title{
Vowel reduction of tense and lax vowels in Kermani accent
}

Vahide Abolhasanizadeh ${ }^{a}{ }^{*}$, Shahid Bahonar University of Kerman, Pazhuhesh square, Kerman, 7616914111, Iran

Anis Masoumi ${ }^{b}$, Allame Tabataba'i University of Tehran, Pazhuhesh square, Kerman, 7616914111, Iran

\section{Suggested Citation:}

Abolhasanizadeh, V. \& Masoumi, A. (2016). Vowel reduction of tense and lax vowels in Kermani accent. New Trends and Issues Proceedings on Humanities and Social Sciences. [Online]. 09, pp 18-26. Available from: www.prosoc.eu

Selection and peer review under responsibility of Prof. Dr. Ali Rahimi, University of Bangkok

${ }^{\circ} 2016$ SciencePark Research, Organization \& Counseling. All rights reserved.

\section{Abstract}

The present article aims to study tense and lax vowels in Kermani accent during the process of vowel reduction. In this study, ten participants (five men and five women with Kermani accent), were asked to pronounce 24 words and to repeat them for 3 times. The vowels of 12 words were in stressed syllables and the vowels of the others were in unstressed ones. The participants' production was recorded using Shure microphone and was analyzed by PRAAT software (Ver. 5.2.24). Then the amount of duration, F1, F2 and F0 of vowels were measured. Results revealed that tense vowels are longer in duration than lax ones, and F0 of vowels in stressed syllables are more than that in unstressed ones. Regarding F1 and F2, therefore, there is no distinguishing behaviour of the tense and lax vowels by which we could recognize them in unstressed syllables.

Keywords: lax vowel; tense vowel; vowel reduction; duration; F0; F1; F2.

* ADDRESS FOR CORRESPONDENCE: Vahide Abolhasanizadeh, Shahid Bahonar University of Kerman, Pazhuhesh square, Kerman, 7616914111, Iran

E-mail address: vahidehabolhasani@yahoo.com / Tel.: +98-34-33202373 
Abolhasanizadeh, V. \& Masoumi, A. (2016). Vowel reduction of tense and lax vowels in Kermani accent. New Trends and Issues Proceedings on Humanities and Social Sciences. [Online]. 09, pp 18-26. Available from: www.prosoc.eu

\section{Introduction}

Kermani accent is a variety of Persian language spoken in Kerman. Mentioned accent and the Standard Persian accent are different in terms of phonological and lexical aspects. In unstressed syllables, the process of centripetal vowel reduction occurs in Kermani accent. In this research, the difference between the lax and tense vowels during the vowel reduction process is analyzed. A brief review of the previous studies is provided as follows:

\section{Literature Review}

An experiment carried out by Pape \& Mooshammer (2006) shows that in German F0 of each tense and lax vowel pairs are rather similar. They also conclude that the low vowels have a significantly lower F0 compared to the high vowels. Comparing the tense and lax vowel pairs in ANOVA shows no significant difference between them. Mooshammer \& Fuchs (2002) believe that German tense vowels become longer in stressed syllables and shortened in unstressed syllables. In unstressed position, the quantity contrast between tense and lax vowels is neutralized whereas the quality contrast is maintained. Ladefoged \& Johnson (2011) believe that lax vowels are different from tense ones in that they are shorter, lower and more centralized than the corresponding tense vowels.

\section{Methodology}

The data of the present research includes $[æ, e, 0, b, u, i]$ vowels. The first three vowels are lax and the others are tense ones. In this study, 10 Kermani speakers ( 5 men and 5 women) repeated each word for three times (Table 1). The subjects' production was recorded by SHURE microphone, and vowels were segmented and labeled with the PRAAT phonetic analysis software (Ver. 5.3.06). Borders of consonants and vowels were determined, and the specific label was defined for each phone. Then the amount of duration, F1, F2 and fundamental frequency of vowels were measured using a PRAAT script., SPSS 16 and Repeated Measure ANOVA were used in order to compare the vowels at hand.

Table 1. Data of the study

\begin{tabular}{|c|c|c|c|c|c|c|}
\hline Vowels & $\begin{array}{c}\text { Kermani } \\
\text { pronunciation }\end{array}$ & $\begin{array}{c}\text { Standard } \\
\text { pronunciation }\end{array}$ & Meaning & $\begin{array}{c}\text { Kermani } \\
\text { pronunciation }\end{array}$ & $\begin{array}{c}\text { Standard } \\
\text { pronunciation }\end{array}$ & Meaning \\
\hline \multirow{2}{*}{ [æ] } & ['sær] & ['sær] & 'head' & [sə'rd] & [sær'p] & 'heads' \\
\hline & ['sæg] & ['sæg] & 'dog' & [sə'gp] & [sæg'p] & 'dogs' \\
\hline \multirow{2}{*}{ [e] } & ['ser] & ['ser] & 'secret' & [sə'rp] & [se'rp] & 'secrets' \\
\hline & ['del] & ['del] & 'heart' & [də'|p] & [de'lp] & 'hearts' \\
\hline & ['kod] & ['kod] & 'code' & [ko'dp] & [ko'dp] & 'codes' \\
\hline [o] & ['boz] & ['boz] & 'goat' & [bo'zp] & [bo'zp] & 'goats' \\
\hline \multirow{3}{*}{ [D] } & ['kpr] & ['kbr] & 'activity' & [kn'rp] & [kn'ro] & 'activities' \\
\hline & ['Jpm] & ['Jpm] & 'dinner' & [ $\left.\mathrm{p}^{\prime} \mathrm{mi}\right]$ & [jp'mi] & $\begin{array}{l}\text { 'a kind of } \\
\text { food' }\end{array}$ \\
\hline & ['jir] & ['Jir] & 'milk' & [Ji'ri] & [ji'ri] & 'milky' \\
\hline [i] & ['sir] & ['sir] & 'garlic' & [si'ri] & [si'ri] & 'fullness' \\
\hline
\end{tabular}


Abolhasanizadeh, V. \& Masoumi, A. (2016). Vowel reduction of tense and lax vowels in Kermani accent. New Trends and Issues Proceedings on Humanities and Social Sciences. [Online]. 09, pp 18-26. Available from: www.prosoc.eu

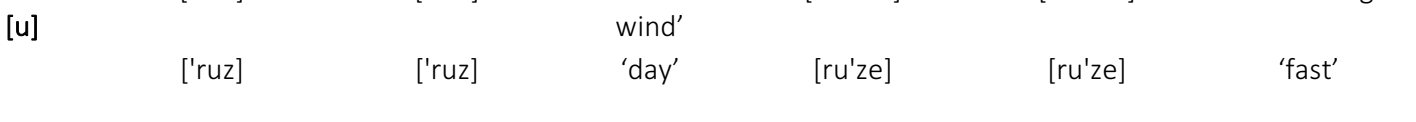

\section{Data analysis}

This section offers some interpretation for the results of the study. Two classifications of vowels, lax and tense, are compared with regard to their behavior in stressed and unstressed syllables. First, the descriptive data are given for all the variables of this study. Then the post-hoc Bonferroni test is used to probe the relationship between the variables.

\subsection{Descriptive statistics}

\subsubsection{Duration}

\subsubsection{Duration of tense vowels in stressed and unstressed syllables}

Table 2 indicates that the mean duration of tense vowels in stressed syllables is more than that in unstressed ones.

Table 2. The mean duration of tense vowels in stressed (S) and unstressed (U) syllables

\begin{tabular}{cccccc}
\hline & Syllable & Mean & Standard deviation & \multicolumn{2}{c}{$95 \%$ Confidence Interval } \\
\cline { 5 - 6 } & & & & Lower bound & Upper bound \\
\hline Tense & S & 208.673 & 8.451 & 191.835 & 225.512 \\
vowels & $\mathrm{U}$ & 133.313 & 4.620 & 124.107 & 142.520 \\
\hline
\end{tabular}

\subsubsection{Duration of lax vowels in stressed and unstressed syllables}

The mean duration of lax vowels in stressed and unstressed syllables is shown in Table 3. According to this table, the mean duration of [æ, e, o] in stressed syllables is more than that in unstressed syllables.

Table 3. The mean duration of lax vowels in stressed (S) and unstressed (U) syllables

\begin{tabular}{cccccc}
\hline & Syllable & Mean & Standard deviation & \multicolumn{2}{c}{ 95\% Confidence Interval } \\
\cline { 5 - 6 } & & & & Lower bound & Upper bound \\
\hline \multirow{2}{*}{$\begin{array}{c}\text { Lax } \\
\text { vowels }\end{array}$} & $\mathrm{S}$ & 206.362 & 7.285 & 191.847 & 220.877 \\
& $\mathrm{U}$ & 120.683 & 5.345 & 110.033 & 131.333 \\
\hline
\end{tabular}

\subsubsection{FO}

Considering fundamental frequency of both lax and tense vowels, Table 4 shows that the mean score of FO in stressed syllables is more than that in unstressed syllables. 
Abolhasanizadeh, V. \& Masoumi, A. (2016). Vowel reduction of tense and lax vowels in Kermani accent. New Trends and Issues Proceedings on Humanities and Social Sciences. [Online]. 09, pp 18-26. Available from: www.prosoc.eu

Table 4. The mean FO of tense and lax vowels in stressed (S) and unstressed (U) syllables

\begin{tabular}{|c|c|c|c|c|}
\hline & Vowels & Syllable & Mean & Standard deviation \\
\hline \multirow{6}{*}{$\begin{array}{l}\text { Tense } \\
\text { vowels }\end{array}$} & \multirow[b]{2}{*}[\mathrm{D}]{} & $S$ & 177.947 & 17.597 \\
\hline & & U & 153.456 & 15.996 \\
\hline & \multirow[b]{2}{*}[u]{} & S & 194.068 & 18.428 \\
\hline & & $U$ & 151.842 & 15.604 \\
\hline & \multirow[b]{2}{*}{ [i] } & S & 175.684 & 16.823 \\
\hline & & $U$ & 145.158 & 14.454 \\
\hline \multirow{6}{*}{$\begin{array}{l}\text { Lax } \\
\text { vowels }\end{array}$} & \multirow[b]{2}{*}{ [æ] } & $S$ & 160.158 & 17.571 \\
\hline & & $U$ & 143.496 & 13.559 \\
\hline & \multirow{3}{*}{ [e] } & S & 179.947 & 18.210 \\
\hline & & $U$ & 159.886 & 16.124 \\
\hline & & $S$ & 177.263 & 16.795 \\
\hline & [o] & $U$ & 151.699 & 15.576 \\
\hline
\end{tabular}

\subsubsection{F1}

According to Table 5, only F1 of [D] decreased in unstressed syllable. In other words, F1 of $[æ, e, o, i, u]$ increased in unstressed syllables, but their variation does not amount to the same thing.

Table 5. The mean F1 of tense and lax vowels in stressed (S) and unstressed (U) syllables

\begin{tabular}{|c|c|c|c|c|}
\hline & Vowels & Syllable & Mean & Standard deviation \\
\hline \multirow{6}{*}{$\begin{array}{l}\text { Tense } \\
\text { vowels }\end{array}$} & \multirow[b]{2}{*}{ [D] } & $S$ & 744 & 114.93 \\
\hline & & U & 619.2 & 198.37 \\
\hline & \multirow{2}{*}[\mathrm{u}]{} & $S$ & 490.3 & 81.28 \\
\hline & & $U$ & 509.2 & 114.5 \\
\hline & \multirow{2}{*}{ [i] } & $S$ & 479.5 & 171.48 \\
\hline & & $U$ & 618.1 & 472.2 \\
\hline \multirow{6}{*}{$\begin{array}{c}\text { Lax } \\
\text { vowels }\end{array}$} & \multirow[b]{2}{*}{ [æ] } & $S$ & 743.8 & 109.57 \\
\hline & & $U$ & 744 & 115.41 \\
\hline & \multirow{3}{*}{ [e] } & $S$ & 542.6 & 70.23 \\
\hline & & $U$ & 550.5 & 76.86 \\
\hline & & $S$ & 555.5 & 54.92 \\
\hline & [o] & $U$ & 570.42 & 121.5 \\
\hline
\end{tabular}

\subsection{4. $F 2$}

Table 6 indicates that F2 of every vowel except [e] increased in unstressed syllables. There was no kind of generalization which we could make about the tense or lax vowels' F2 in stressed and unstressed syllables. 
Abolhasanizadeh, V. \& Masoumi, A. (2016). Vowel reduction of tense and lax vowels in Kermani accent. New Trends and Issues Proceedings on Humanities and Social Sciences. [Online]. 09, pp 18-26. Available from: www.prosoc.eu

Table 6. The mean F2 of tense and lax vowels in stressed (S) and unstressed (U) syllables

\begin{tabular}{|c|c|c|c|c|}
\hline & Vowels & Syllable & Mean & Standard deviation \\
\hline \multirow{6}{*}{$\begin{array}{l}\text { Tense } \\
\text { vowels }\end{array}$} & \multirow[b]{2}{*}{ [D] } & $S$ & 1660.7 & 149.6 \\
\hline & & $U$ & 1743.1 & 198.98 \\
\hline & \multirow[b]{2}{*}[u]{} & $S$ & 1465.8 & 411.4 \\
\hline & & $U$ & 1659 & 361.3 \\
\hline & \multirow{2}{*}{ [i] } & $S$ & 2249.7 & 169.9 \\
\hline & & U & 2318.3 & 192.5 \\
\hline \multirow{6}{*}{$\begin{array}{c}\text { Lax } \\
\text { vowels }\end{array}$} & \multirow{3}{*}{ [æ] } & $\mathrm{S}$ & 1373.3 & 253.16 \\
\hline & & $U$ & 1447.8 & 357.7 \\
\hline & & $S$ & 1890.5 & 174.27 \\
\hline & \multirow[t]{2}{*}{ [e] } & U & 1811.3 & 211.4 \\
\hline & & $S$ & 1426.73 & 444.42 \\
\hline & [o] & U & 1602 & 430.6 \\
\hline
\end{tabular}

\subsection{Analytic statistics}

\subsubsection{Duration}

\subsubsection{Duration of stressed and unstressed tense vowels}

By analyzing the effect of stress on Kermani vowels, one can conclude that the duration of tense vowels in unstressed syllables is less than that in stressed syllables. The repeated measure ANOVA shows that the effect of stress on duration of tense vowels is significant $(p=0.000)$ (Table 7$)$.

Table 7. The results of comparing the mean duration of tense vowels in stressed and unstressed syllables

\begin{tabular}{cccccc}
\hline & $\begin{array}{c}\text { Type III Sum } \\
\text { of Squares }\end{array}$ & df & Mean Square & F & Sig. \\
\hline Stressed and unstressed tense vowels & 212967.360 & 1 & 212967.360 & 98.905 & 0.000 \\
\hline
\end{tabular}

Based on the post-hoc Bonferroni test, the mean duration of tense vowels in stressed syllables is $75.360 \mathrm{~ms}$ more than that in unstressed syllables.

\subsubsection{Duration of stressed and unstressed lax vowels}

In Table 8, we see the results of comparing the mean duration of lax vowels in stressed and unstressed syllables. Based on the results of the repeated measure ANOVA, the effect of stress on duration of lax vowels is significant $(p=0.000)$.

Table 8. The results of comparing the mean duration of lax vowels in stressed and unstressed syllables

\begin{tabular}{cccccc}
\hline & $\begin{array}{c}\text { Type III Sum } \\
\text { of Squares }\end{array}$ & df & Mean Square & F & Sig. \\
\hline Stressed and unstressed lax vowels & 275279.130 & 1 & 275279.130 & 157.191 & 0.000 \\
\hline
\end{tabular}

The post-hoc Bonferroni test shows that the mean score of lax vowels' duration in stressed syllable is $85.678 \mathrm{~ms}$ more than that in unstressed syllables. 


\subsubsection{FO}

\subsubsection{Tense vowels}

Table 9 indicates the results of comparing the mean FO of tense vowels in stressed and unstressed syllables. The results are demonstrated in the following lines:

Table 9. The results of comparing the mean F0 of tense vowels in stressed and unstressed syllables

\begin{tabular}{ccccccc}
\hline & Vowels & $\begin{array}{c}\text { Type III Sum of } \\
\text { Squares }\end{array}$ & df & Mean Square & F & Sig. \\
\hline \multirow{2}{*}{ Tense } & {$[\mathrm{b}]$} & 5698.292 & 1 & 5698.292 & 29.435 & 0.000 \\
vowels & {$[\mathrm{u}]$} & 16938.483 & 1 & 16938.483 & 26.318 & 0.000 \\
& {$[\mathrm{i}]$} & 8852.632 & 1 & 8852.632 & 9.583 & 0.006 \\
\hline
\end{tabular}

I) According to the repeated measure ANOVA test, the difference between F0 of the tense vowel $[\mathrm{b}]$, in stressed and unstressed syllables is significant $(p=0.000)$. The post-hoc Bonferroni test shows that F0 of this vowel in stressed syllable is $24.491 \mathrm{~Hz}$ more than that in unstressed one (Table 9).

II) The repeated measure ANOVA test shows that the difference between the amount of FO of [u], in stressed and unstressed syllables is significant $(p=0.000)$. Based on the post-hoc Bonferroni test, F0 of [u] in stressed syllables is $42.226 \mathrm{~Hz}$ more than that in unstressed syllables.

III) Based on Table 13 and the repeated measure ANOVA test, the significance of the difference between $\mathrm{FO}$ of [i] in stressed and unstressed syllables, is obvious $(p=0.006)$. The post-hoc Bonferroni test gives evidence that FO of [i] in stressed syllable, is $30.526 \mathrm{~Hz}$ more than that in unstressed syllables.

\subsubsection{Lax vowels}

Table 10 shows the results of comparing the mean FO of lax vowels in stressed and unstressed syllables. According to the data in the table below, it is inferred that:

Table 10. The results of comparing the mean FO of lax vowels in stressed and unstressed syllablesE

\begin{tabular}{lcccccc}
\hline & Vowels & $\begin{array}{c}\text { Type III Sum of } \\
\text { Squares }\end{array}$ & df & Mean Square & F & Sig. \\
\hline \multirow{3}{*}{ Lax vowels } & {$[æ]$} & 2637.302 & 1 & 2637.302 & 8.801 & 0.008 \\
& {$[\mathrm{e}]$} & 3823.369 & 1 & 3823.369 & 4.062 & 0.059 \\
& {$[\mathrm{o}]$} & 6208.378 & 1 & 6208.378 & 18.007 & 0.000 \\
\hline
\end{tabular}

I) The difference between F0 of [æ], in stressed and unstressed syllables is significant $(p=0.008)$. The post-hoc Bonferroni test also indicates that F0 of vowel mentioned above, in stressed position, is $16.662 \mathrm{~Hz}$ more than that in unstressed one.

II) The repeated measure ANOVA test indicates that the difference between $\mathrm{FO}$ of [e] in stressed and unstressed syllables is significant (P: 0.059). In stressed position, F0 of [e] is $20.061 \mathrm{~Hz}$ more than that in unstressed position (based on the post-hoc Bonferroni test). 
III) The difference between F0 of [o] in stressed and unstressed syllables is, according to the repeated measure ANOVA, significant $(p=0.000)$. Based on the post-hoc Bonferroni test, F0 of this vowel, in stressed syllable, is $25.564 \mathrm{~Hz}$ more than that in unstressed syllables.

\subsubsection{F1}

\subsubsection{Tense vowels}

In Table 11, the results of comparing the mean F1 of tense vowels in stressed and unstressed syllables is shown. Based on this table it is concluded that:

Table 11. The results of comparing the mean F1 of tense vowels in stressed and unstressed syllables

\begin{tabular}{ccccccc}
\hline & Vowels & $\begin{array}{c}\text { Type III Sum of } \\
\text { Squares }\end{array}$ & df & Mean Square & F & Sig. \\
\hline Tense vowels & {$[\mathrm{D}]$} & 140125.444 & 1 & 140125.444 & 6.671 & 0.019
\end{tabular}


of mentioned vowel in unstressed syllable is $0.2 \mathrm{~Hz}$ more than that in stressed syllable. The reason is this vowel's slight tendency toward the [ə].

II) According to the repeated measure ANOVA test, the mean F1 of [e] differs in stressed and unstressed syllables and their difference is significant $(p=0.032)$. The post-hoc Bonferroni test shows that the mean $\mathrm{F} 1$ of this vowel in stressed syllable is $7.9 \mathrm{~Hz}$ less than that in unstressed ones. Decrease of the F1, regarding this vowel, is due to this vowel's gradual shift toward the centre of the vowel space as a result vowel reduction.

III) According to the repeated measure ANOVA test, the difference between the amount of F1 in [o], in stressed and unstressed syllables, is not significant. Based on the post-hoc Bonferroni test, in unstressed position, F1 of this vowel is $14.92 \mathrm{~Hz}$ more than that in stressed positions.

\subsubsection{F2}

\subsubsection{Tense vowels}

Table 13 indicates the results of comparing the mean F2 of tense vowels in stressed and unstressed syllables. According to this table it is inferred that:

Table 13. The results of comparing the mean F2 of tense vowels in stressed and unstressed syllables

\begin{tabular}{lcccccc}
\hline & Vowels & $\begin{array}{c}\text { Type III Sum of } \\
\text { Squares }\end{array}$ & df & Mean Square & F & Sig. \\
\hline \multirow{3}{*}{ Tense vowels } & {$[\mathrm{D}]$} & 61091.361 & 1 & 61091.361 & 2.610 & 0.125 \\
& {$[\mathrm{u}]$} & 336013.444 & 1 & 336013.444 & 7.669 & 0.013 \\
& {$[\mathrm{i}]$} & 158935.111 & 1 & 158935.111 & 6.996 & 0.017 \\
\hline
\end{tabular}

I) The repeated measure ANOVA shows that in case of [o], the difference between the mean $\mathrm{F} 2$ of this vowel, in stressed and unstressed syllable, is not significant. The post-hoc Bonferroni test shows that the mean F2 of the mentioned vowel in unstressed syllable is $82.4 \mathrm{~Hz}$ more than that in stressed syllable. The reason is this vowel's tendency toward the [ə].

II) According to the repeated measure ANOVA test, the mean F2 of [u] differs in stressed and unstressed syllables and their difference is significant $(p=0.013)$. The post-hoc Bonferroni test shows that the mean F2 of this vowel in stressed syllable is $193.2 \mathrm{~Hz}$ less than that in unstressed ones. Increase of the F2, concerning this vowel, in unstressed position, is due to this vowel's gradual shift toward the centre of the vowel space as a result vowel reduction.

III) According to the repeated measure ANOVA test, the difference between the amount of F2 in [i], in stressed and unstressed syllables, is significant $(p=0.017)$. Based on the post-hoc Bonferroni test, in unstressed position, the amount of F2 of this vowel is $68.6 \mathrm{~Hz}$ more than that in stressed positions.

\subsubsection{Lax vowels}

Table 14 shows the amount of $F 2$ of lax vowels in stressed and unstressed syllables. By considering this table, it is obvious that:

Table 14. The results of comparing the mean F2 of lax vowels in stressed and unstressed syllables

\begin{tabular}{lcccccc}
\hline & Vowels & $\begin{array}{c}\text { Type III Sum } \\
\text { of Squares }\end{array}$ & df & Mean Square & F & Sig. \\
\hline \multirow{3}{*}{ Lax vowels } & {$[æ]$} & 24843.764 & 1 & 24843.764 & 1.263 & 0.277 \\
& {$[\mathrm{e}]$} & 56485.444 & 1 & 56485.444 & 4.995 & 0.039
\end{tabular}


Abolhasanizadeh, V. \& Masoumi, A. (2016). Vowel reduction of tense and lax vowels in Kermani accent. New Trends and Issues Proceedings on Humanities and Social Sciences. [Online]. 09, pp 18-26. Available from: www.prosoc.eu

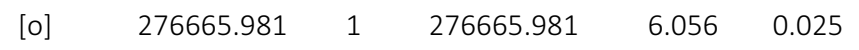

I) According to the repeated measure ANOVA test, the difference between F2 of [æ] in stressed and unstressed syllables is not significant $(p=0.277)$. The mean F2 of this vowel in unstressed syllable is $74.5 \mathrm{~Hz}$ more than that in stressed syllable (based on the post-hoc Bonferroni test). This fact is the result of this vowel's gradual shift toward the [ə] as the process of vowel reduction occurs in this accent.

II) Based on the repeated measure ANOVA test, the difference between [e] vowel's F2 in stressed and unstressed syllables is significant $(p=0.039)$. According to the post-hoc Bonferroni test, in stressed syllable, the mean F2 of [e] is $79.2 \mathrm{~Hz}$ more than that in unstressed syllable. It is believed that the reason for this change is the occurrence of centripetal vowel reduction in Kermani accent.

III) The F2 of [o] differs in stressed and unstressed syllables. Based on the repeated measure ANOVA test, we found that their difference is significant $(p=0.025)$. The post-hoc Bonferroni test indicates that the mean F2 of this vowel, in comparison with stressed syllables, is $175.27 \mathrm{~Hz}$ more in unstressed syllables. The increasing of F2 of [o] in unstressed syllables is due to the vowel reduction.

\section{Conclusion}

According to this study, regardless of stressed or unstressed syllable in which they occur, tense vowels are longer in duration than lax ones. In addition, the duration of tense vowels in stressed syllables is more than that in unstressed syllables. An experiment carried out by Mooshammer \& Fuchs (2002) shows the same result in German language. In stressed syllables, F0 of vowels is more than that in unstressed syllables and FO of both tense and lax vowels decreased in the process of vowel reduction. It is worth mentioning that tense and lax vowels in Kermani accent, as a whole, don't behave in a way by which one could distinguish one tense vowel from the other lax vowel by their F0 change in stressed and unstressed syllables. Pape \& Mooshammer (2006) also found that in German language, FO is not used as a perceptual cue to distinguish tense and lax vowels. In unstressed syllable, the mean F1 of [D] tense vowel is decreased and F1 of the other vowels is increased in this position compared to stressed syllable. In unstressed syllables, only the mean F2 of [e] decreased and the mean F2 of the other vowels increased in unstressed positions. By this way, regarding F1 and F2, like F0, there is no generalization by which we could make about the tense and lax vowels' behavior in unstressed syllables.

\section{Reference}

Ladefoged, P. \& Johnson, K. (2011). A course in phonetics. Cengage learning.

Mooshammer, C. \& Fuchs, S. (2002). Stress distinction in German: Simulating kinematic parameters of tongue-tip gestures. Journal of Phonetics, 30(3), 337-355.

Pape, D. \& Mooshammer, C. (2006). Intrinsic F0 differences for German tense and lax vowels. Proceedings of the 7th International Seminar on Speech Production Ubatuba, 271-278. 